https://helda.helsinki.fi

\title{
Extending the hydrogen storage limit in fullerene
}

\section{Gaboardi, Mattia}

2017-08

Gaboardi , M , Amade , N S , Aramini , M , Milanese , C, Magnani , G , Sanna , S , Ricco , M \& Pontiroli , D 2017 , ' Extending the hydrogen storage limit in fullerene ' , Carbon, vol. 120 , pp. 77-82 . https://doi.org/10.1016/j.carbon.2017.05.025

http://hdl.handle.net/10138/308093

https://doi.org/10.1016/j.carbon.2017.05.025

cc_by_nc_nd

acceptedVersion

Downloaded from Helda, University of Helsinki institutional repository.

This is an electronic reprint of the original article.

This reprint may differ from the original in pagination and typographic detail.

Please cite the original version. 


\section{Extending the hydrogen storage limit in fullerene}

Mattia Gaboardi, ${ }^{* 1}$ Nicola Sarzi-Amadé, ${ }^{2}$ Matteo Aramini, ${ }^{3,1}$ Chiara Milanese, ${ }^{4}$ Giacomo Magnani, ${ }^{2}$ Samuele Sanna, ${ }^{5}$ Mauro Riccò, ${ }^{2}$ and Daniele Pontiroli. ${ }^{2}$

1. ISIS Facility, Rutherford Appleton Laboratory, Chilton, Didcot, Oxfordshire OX11 0QX, United Kingdom.

2. Dipartimento di Scienze Matematiche, Fisiche ed Informatiche, University of Parma, Parco Area delle Scienze, 7/a, 43124 Parma, Italy.

3. Department of Physics, University of Helsinki, Gustaf Hällströmin, P.O. box 64, 00014 Helsinki, Finland.

4. Pavia Hydrogen Lab, CSGI \& Università di Pavia, Dipartimento di Chimica, Sezione di Chimica Fisica, Viale Taramelli, 16, 27100 Pavia, Italy.

5. Department of Physics and Astronomy, University of Bologna, 40127 Bologna, Italy

$\mathrm{Li}_{6} \mathrm{C}_{60}$ has been chosen as the most representative system to study the hydrogenation mechanism in alkali-cluster intercalated fullerides. We present here a muon spin relaxation ( $\mu S R)$ experiment that hints the chance to achieve a higher storage capacity on fullerene with respect to the values suggested in literature. Moreover, a linear relationship between the muonium adduct radical hyperfine frequency and the level of $C_{60}$ hydrogenation was found and it can be exploited to probe the $C_{60}$ hydrogenation level, giving more credit to this technique in the field of hydrogen storage materials.

\section{Introduction}

Alkali cluster intercalated fullerides recently demonstrated to be fascinating materials for their use in the field of reversible hydrogen storage.[1-6] In these compounds, hydrogen is absorbed through a complex chemisorption process, involving the dissociation of hydrogen molecules operated by intercalated alkali clusters, the partial segregation of a metal hydride phase, and the formation of hydrogenated $\mathrm{C}_{60}$ (hydrofullerene). Hydrogenated fullerenes are mostly studied for their ability to store large quantities of hydrogen available under mild conditions of temperature and pressure. Recently, they have also been exploited as fluorophores in light emitting diodes, being their energy gap tuneable with the number of chemisorbed hydrogens.[7] Here, we consider $\mathrm{Li}_{6} \mathrm{C}_{60}$ as a model system to investigate the hydrogen absorption properties in this class of compounds. This compound is able to absorb about $5 \mathrm{wt} \% \mathrm{H}_{2}$ after a $10 \mathrm{~h}$ isotherm at $350{ }^{\circ} \mathrm{C}$ and $100 \mathrm{bar}_{2}$ (corresponding to about 40 hydrogen atoms per formula unit), with an onset temperature of $\sim 140$ ${ }^{\circ} \mathrm{C}$, virtually reaching the plateau at $5.2 \mathrm{wt} \% \mathrm{H}_{2}$ (about 42 hydrogen atoms) for longer isotherm. $[5,8]$ Its desorption is complete and well characterized by an endothermic peak, having a dehydrogenation enthalpy of about $63 \mathrm{~kJ} / \mathrm{mol} \mathrm{H}_{2}$, with an onset temperature of $\sim 270-306^{\circ} \mathrm{C}$, 
depending on the synthetic route.[8,9] The in situ neutron powder diffraction (NPD) study on $\mathrm{Li}_{6} \mathrm{C}_{60}$ under deuterium pressure, suggested the initial formation of a stable $\mathrm{Li}_{6} \mathrm{C}_{60} \mathrm{D}_{\mathrm{y}}$ single phase (y $\approx 8$ ) starting at around $140{ }^{\circ} \mathrm{C}$, followed by the partial segregation of LiD above $200{ }^{\circ} \mathrm{C}$, the subsequent increase of the hydrogen amount chemisorbed on $\mathrm{C}_{60}$, and the structural transition of the hydrofulleride to a $b c c$ lattice.[5] This appears to be in contrast with the theoretical model calculated by Wang et al., where the Li atoms are coordinated to $\mathrm{C}_{60}$ pentagons, inward (i.e. near the internal surface) and outward the hydrofullerene molecule and some of them are able to bond hydrogen atoms.[10] It is worth to point out that the production of the hydride, although evident in the case of $\mathrm{Na}_{10} \mathrm{C}_{60}$, may not be obvious by the X-ray diffraction analysis, due to the very small scattering factor of $\mathrm{Li}$. The absorption kinetics inevitably slows down when $\mathrm{Li}$ ions that belong to intercalated clusters begin to form the hydride but can be significantly improved by adding small amounts of $\mathrm{Pt}$ and $\mathrm{Pd}$ to $\mathrm{Li}_{6} \mathrm{C}_{60}$. In this case, the catalyst promotes the $\mathrm{H}_{2}$ dissociation process, originally operated by the Li clusters, even when their nuclearity is largely reduced due to $\mathrm{Li}$ conversion into $\mathrm{LiH}$. The gravimetric storage capacity is related to the number of hydrogen atoms bound to $\mathrm{C}_{60}$ and to the amount of metal hydride formed at the expenses of the intercalated $\mathrm{Li}$, following the equation $L i_{6} C_{60}+\frac{y}{2} H_{2} \rightleftharpoons L i_{6-\alpha} C_{60} H_{y-\alpha}+\alpha L i H$. The hydrogen chemisorption by fullerene occurs through the saturation of the carbon $\mathrm{sp}^{2}$ hybrid orbitals and the subsequent formation of $\mathrm{C}-\mathrm{H}$ bonds. Thus, in principle, only an even number of hydrogen atoms can be bound to $\mathrm{C}_{60}$.[11] If lithium did not react with hydrogen, forming $\mathrm{LiH}($ i.e. $\alpha=0$ ), the hydrogenation degree on $\mathrm{C}_{60}$ would lead to $\mathrm{y} \approx 42\left(5.2 \mathrm{wt} \% \mathrm{H}_{2}\right)$ and to $\mathrm{y} \approx 48$ when $\mathrm{Pd}$ is added as catalyst $(\sim 5.9$ $\mathrm{wt} \% \mathrm{H}_{2}$ ). Anyway, this is not the case, as proved by NPD.[5] Moreover, recent nuclear magnetic resonance (NMR) data investigations suggest that about 2 molar fractions of $\mathrm{LiH}$ are formed in $\mathrm{Li}_{6} \mathrm{C}_{60}$ after hydrogenation (i.e. $\alpha=2, \mathrm{y}=40$ ). [12] In the case of $\mathrm{Pt}-\mathrm{Li}_{6} \mathrm{C}_{60}$, whether or not the hydrogenation proceeds with additional segregation of $\mathrm{LiH}$ remains unclear. A complete reaction of lithium with hydrogen would lead to $\mathrm{C}_{60} \mathrm{H}_{42}+6 \mathrm{LiH}$. Anyway, the temperature dependence of the NMR spin-lattice relaxation rate $\left(1 / \mathrm{T}_{1}\right)$ in hydrogenated $\mathrm{Pt}_{0.1} \mathrm{Li}_{6} \mathrm{C}_{60}$, allowed us to extract $\alpha=3$, suggesting the formation of $\mathrm{Li}_{3} \mathrm{C}_{60} \mathrm{H}_{45}+3 \mathrm{LiH}$ (manuscript in preparation). Although as minor species, hydrofullerene molecules with higher hydrogen content, such as $\mathrm{C}_{60} \mathrm{H}_{48}$, have been detected by Teprovich et al. during the study of $\mathrm{Li}_{6} \mathrm{C}_{60} \cdot[8]$

Beyond hydrogen absorption kinetic measurements, muon spin relaxation ( $\mu \mathrm{SR})$ spectroscopy has successfully been exploited to study fullerides and turned out to be a powerful technique to study hydrogen storage materials, other than being particularly suitable to insight the hydrogen chemistry in carbon nanostructures.[13-16] When a positive muon $\left(\mu^{+}\right)$thermalizes into materials having low electronic density, it can bind to an electron forming a light isotope of hydrogen, known as 
muonium $(\mathrm{Mu})$. The latter can be hosted in the lattice interstitial spaces as well as forming a chemically bound species, i.e. a Mu adduct radical. Muonium reacts with fullerene forming $\mathrm{C}_{60}-\mathrm{Mu}$ adduct radicals and endohedral muonium $\left(\mathrm{Mu} @ \mathrm{C}_{60}\right.$, i.e. a $\mathrm{Mu}$ trapped at the centre of $\mathrm{C}_{60}$ icosahedron, showing nearly-free hydrogen features).[17] A different muon-electron spin hyperfine coupling allows to identify and differentiate these species. For a hydrogen-saturated fullerene, the formation of radicals is no longer expected, whilst the existence of $\mathrm{Mu} @ \mathrm{C}_{60}$ has not been investigated so far. With this study, we aim to verify the hydrogenation limit of fullerene by measuring the formation of muonic radical species, exploiting the unique power of $\mu$ SR technique for the study of hydrogen storage materials.

\section{Methods}

$\mathrm{C}_{60}\left(99.95 \%\right.$ purity) and $\mathrm{C}_{60} \mathrm{H}_{\mathrm{x}}$ (where $\mathrm{x} \approx 39$, as average of a distribution of hydrofullerenes) powders were purchased from M.E.R. Corporation. Lithium metal (99\% purity), platinum (99.99\%), and palladium (99.98\%) were purchased from Sigma Aldrich. $\mathrm{Li}_{6} \mathrm{C}_{60}, \mathrm{Pd}_{\mathrm{x}} \mathrm{Li}_{6} \mathrm{C}_{60}$, and $\mathrm{Pt}_{\mathrm{x}} \mathrm{Li}_{6} \mathrm{C}_{60}$ were synthesized by mixing $\mathrm{C}_{60}$ and lithium (or the respective $\mathrm{LiM}_{\mathrm{x}}$ alloys, where $\mathrm{M}=$ $\mathrm{Pd}, \mathrm{Pt}$ and $\mathrm{x}=0.17$ and 0.07 respectively) in a high-energy ball milling (Fritsch Mini-Mill Pulverisette23), as described elsewhere.[9] The non-identical transition metal stoichiometries depend on the different capabilities of Li to give liquid azeotropic mixtures with Pt and Pd metals, however we did not observe a relevant dependence of these stoichiometries on the maximum $\mathrm{H}_{2}$ absorption values. Hydrogenated $\mathrm{Li}_{6} \mathrm{C}_{60}, \mathrm{Pd}_{\mathrm{x}} \mathrm{Li}_{6} \mathrm{C}_{60}$, and $\mathrm{Pt}_{\mathrm{x}} \mathrm{Li}_{6} \mathrm{C}_{60}$ were obtained by heating the synthesized compounds at $350{ }^{\circ} \mathrm{C}\left(5^{\circ} \mathrm{C} / \mathrm{min}\right.$ rate, $10 \mathrm{~h}$ isotherm $)$ under $100 \mathrm{bar} \mathrm{H}_{2}$, in a PCTPro2000 manometric instrument by Setaram. In order to obtain intermediate levels of hydrogenation on $\mathrm{C}_{60}, \mathrm{Li}_{6} \mathrm{C}_{60}$ underwent two partial hydrogenations at $190{ }^{\circ} \mathrm{C}\left(60 \mathrm{bar} \mathrm{H}_{2}\right)$ and at $280{ }^{\circ} \mathrm{C}\left(100\right.$ bar $\left.\mathrm{H}_{2}\right)$. X-ray powder diffractions were carried out by means of a Bruker D8 Discover instrument $\left(\mathrm{Cu}-\mathrm{K}_{\alpha 1}\right.$ radiation), working in Debye-Scherrer geometry and equipped with an area detector (GADDS). In case of partially hydrogenated $\mathrm{Li}_{6} \mathrm{C}_{60} \mathrm{H}_{\mathrm{y}}$ the measurements were carried out on a Xenox NanoinXider small angle and wide angle diffractometer equipped with an area detector. Glass capillaries were filled with powder and sealed in Ar. The measurements were performed while spinning, collecting data for several hours per frame. The $\mu$ SR experiments were carried out at the ISISRutherford Appleton Laboratory (Didcot, UK). The 100\% spin-polarized pulsed beam of this facility is optimized to study the muon spin evolution over long time-scales. Pt and Pd doped compounds were measured on the Argus spectrometer at the RIKEN-RAL Muon facility. The total experimental muon polarization asymmetry was established to be $23.10(15) \%$, estimated on a separate transverse field (TF) experiment on pure silver. The baseline, due to muons stopping 
outside the sample, was measured to be $5.76(11) \%$ of the total polarization at zero field (ZF), whereas its longitudinal field (LF) dependence was measured applying a field in the range 0-3.8 $\mathrm{kG}$ and was considered in order to extract the repolarization data. The semi-hydrogenated compounds of $\mathrm{Li}_{6} \mathrm{C}_{60}$ were measured on the EMU spectrometer. In that case, the total experimental asymmetry and baseline were estimated to be 23.48(3) and 7.34(5)\% respectively. About 200-400 $\mathrm{mg}$ of sample was pressed and sealed in an air-tight silver-coated aluminium cell, capped by a kapton window. The muon polarization was followed by plotting the asymmetry function, expressed as $A(t)=\frac{N_{b}(t)-\alpha N_{f}(t)}{N b(t)+a N f(t)}$, where $N_{b / f}$ is the backward/forward collected counts and $\alpha$ is a geometrical parameter, calibrated for each temperature by fitting the oscillation observed under the application of a $20 \mathrm{G}$ transversal field. Time dependent polarizations were analysed by means of the WiMDA software,[18] after correcting for the double-pulsed structure of the muon beam.

\section{Results and Discussion}

The hydrogen absorption runs of $\mathrm{Pt}_{\mathrm{x}} \mathrm{Li}_{6} \mathrm{C}_{60}$ and $\mathrm{Pd}_{\mathrm{x}} \mathrm{Li}_{6} \mathrm{C}_{60}$ samples at $350{ }^{\circ} \mathrm{C}$ and 100 bar $\mathrm{H}_{2}$ yield to achieve about 5.8(1) $\mathrm{wt} \% \mathrm{H}_{2}$ for both the samples, as shown in Figure 1(a) and $(b)$ respectively. These values are in agreement with the ones previously reported for $\mathrm{Pt}$ and $\mathrm{Pd}$ doped $\mathrm{Li}_{6} \mathrm{C}_{60}$.[9]The hydrogenation of $\mathrm{Li}_{6} \mathrm{C}_{60}$ at $190{ }^{\circ} \mathrm{C}$ and 60 bar $\mathrm{H}_{2}$ leads to about $1.7 \mathrm{wt} \% \mathrm{H}_{2}$ stored after 10.5 hours (Figure $1(c)$ ), while the hydrogenation at $280{ }^{\circ} \mathrm{C}$ and 100 bar $\mathrm{H}_{2}$ allows to achieve about $3.5 \mathrm{wt} \%$ $\mathrm{H}_{2}$ after the same period of time (see Figure $1(d)$ ). Considering the weight contributions of the transition metals, the number of the absorbed hydrogen atoms per formula unit are approximately 48 for $\mathrm{Pd}_{\mathrm{x}} \mathrm{Li}_{6} \mathrm{C}_{60}$ and 50 for $\mathrm{Pt}_{\mathrm{x}} \mathrm{Li}_{6} \mathrm{C}_{60}$. It is worth to point out that these values do not represent the number of hydrogen atoms attached to $\mathrm{C}_{60}$, as part of them are involved in the formation of the $\mathrm{LiH}$ secondary phase. Thus, we can assume the formation of $\mathrm{C}_{60} \mathrm{H}_{48-\mathrm{y}}$ and $\mathrm{C}_{60} \mathrm{H}_{50-\mathrm{y}}$ for $\mathrm{Pd}$ and $\mathrm{Pt}$ decorated $\mathrm{Li}_{6} \mathrm{C}_{60}$ respectively, with $y$ reaching a maximum of six.

The X-ray diffraction patterns of these samples are reported in Figure 1(e) and confirms a transition from the face centred cubic $(f c c)$ structure of $\mathrm{Li}_{6} \mathrm{C}_{60}$ (as well for $\mathrm{Pt} / \mathrm{Pd}$ doped $\mathrm{Li}_{6} \mathrm{C}_{60}$ ) to body centred cubic $(b c c)$ structure upon hydrogenation. 

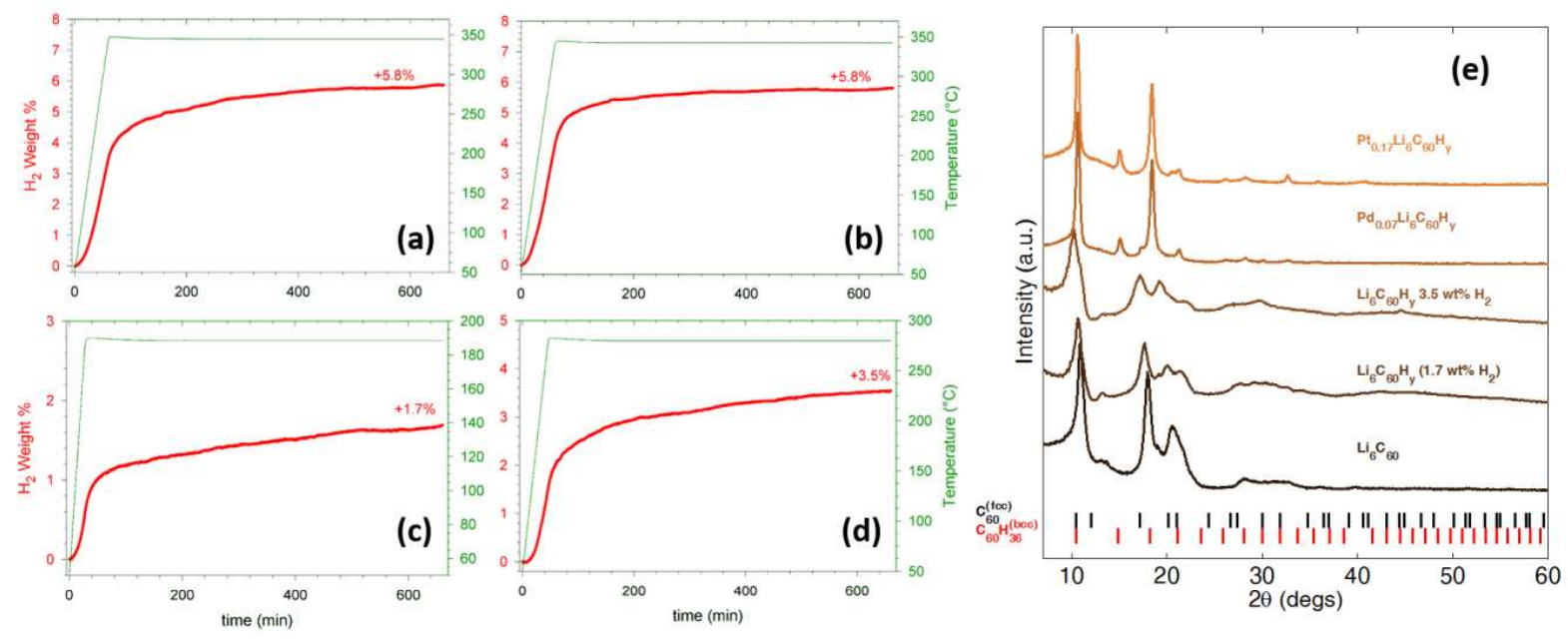

Figure 1: kinetic hydrogen absorption curves for $P t_{x} L i_{6} C_{60}(a)$ and $P d_{x} L i_{6} C_{60}(c)$ hydrogenated at $350{ }^{\circ} \mathrm{C}, 100$ bar $\mathrm{H}_{2}$, and $\mathrm{Li}_{6} \mathrm{C}_{60}$ hydrogenated at $280{ }^{\circ} \mathrm{C}, 100$ bar $\mathrm{H}_{2}$ (b) and190 ${ }^{\circ} \mathrm{C}, 60$ bar $\mathrm{H}_{2}$ (d). (e) $X$-ray diffraction patterns of $\mathrm{Li}_{6} \mathrm{C}_{60}$, partially hydrogenated $\mathrm{Li}_{6} \mathrm{C}_{60}$ (at 1.7 and $3.5 \mathrm{wt} \% \mathrm{H}_{2}$ ), and fully hydrogenated $\mathrm{Pd}_{x} \mathrm{Li}_{6} \mathrm{C}_{60}$ and $\mathrm{Pt}_{0.7} \mathrm{Li}_{6} \mathrm{C}_{60}\left(5.8 \mathrm{wt} \% \mathrm{H}_{2}\right)$. Fcc and bcc reflections are also highlighted.

$\mathrm{Li}_{6} \mathrm{C}_{60}, \mathrm{Pt}_{\mathrm{x}} \mathrm{Li}_{6} \mathrm{C}_{60}$, and $\mathrm{Pd}_{\mathrm{x}} \mathrm{Li}_{6} \mathrm{C}_{60}$ share the same $f c c$ structure, with no apparent differences. The $\mathrm{X}-$ ray diffraction patterns of $\mathrm{C}_{60} \mathrm{H}_{39}, \mathrm{Pt}_{\mathrm{x}} \mathrm{Li}_{6} \mathrm{C}_{60} \mathrm{H}_{\mathrm{y}}$, and $\mathrm{Pd}_{\mathrm{x}} \mathrm{Li}_{6} \mathrm{C}_{60} \mathrm{H}_{\mathrm{y}}$ samples show the typical bcc structure of $\mathrm{C}_{60} \mathrm{H}_{36}$ hydrofullerite,[19] with a lattice constant of $a=11.83(3) \AA$ (see ref . [4] for $\mathrm{C}_{60} \mathrm{H}_{39}$ ). The partially hydrogenated $\mathrm{Li}_{6} \mathrm{C}_{60}$ compounds exhibit a mixture of the $f c c$ and $b c c$ structures, as already observed in ref. [5], due to the first order type transition occurring between two line phases upon hydrogenation.

The ZF muon spin asymmetry amplitude of all the samples shows a remarkable missing fraction, i.e. only a fraction of the total asymmetry is detected. This is a clear evidence that the muon undergoes a hyperfine interaction with unpaired electrons which can originate either from $\mathrm{Mu}$ or from the formation of an adduct radical.[20] The observed ZF/LF muon spin evolutions did not show remarkable features and were fit according to different decaying functions, depending on the sample (e.g. see Figure 2). In particular, non-hydrogenated samples were fit according to a simple lorentzian decay. Their respective hydrogenated phases were fit according to the sum of a flat baseline and a lorentzian decay. Unlike the others, $\mathrm{C}_{60} \mathrm{H}_{39}$ was better fit according to a stretched lorentzian decay $(\beta=0.43(13))$, a function usually adopted in case of disordered systems. This can be explained by the inhomogeneous nature of the sample, given by the wide distribution of hydrofullerenes and their respective isomers. It is worth to point out the increased rate of relaxation 
of hydrogenated compounds compared to the non-hydrogenated ones, although it was not possible to extrapolate a clear trend as a function of the hydrogenation grade.

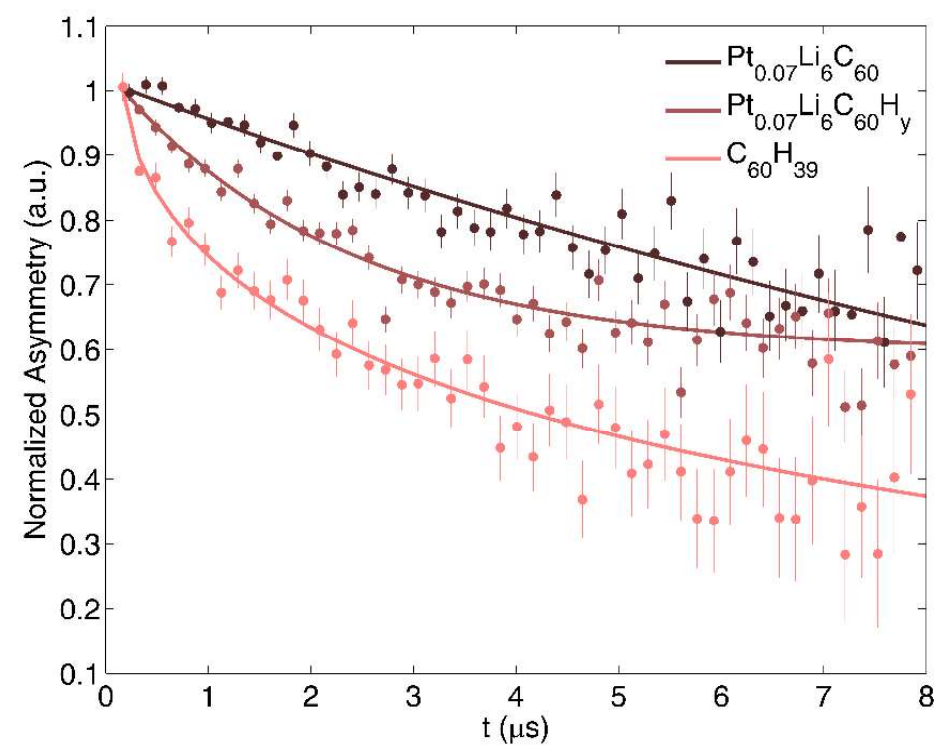

Figure 2: ZF asymmetries for selected samples and their fits according to lorentzian $\left(P d_{x} L i_{6} C_{60}\right.$ and $\left.P d_{x} L_{6} C_{60} H_{y}\right)$ and stretched exponential $\left(C_{60} H_{39}\right)$ decays. In order to have a better comparison, data have been normalized to the total amplitude, thus not showing the missing fraction.

The ZF missing fraction of the muons can be repolarized by the application of a longitudinal magnetic field that decouples the hyperfine interaction between the muon and the electron spins. This technique allows probing the local magnetic field distribution experienced by the implanted muons spin, thus allowing the identification of the free muons, weakly interacting with the environment, from those residing in a paramagnetic environment. The latter being the free muonium itself (repolarizing at $1585 \mathrm{G}$ ) or the result of its chemical reaction, which generally produces a radical (repolarizing in the $200-1200 \mathrm{G}$ range). In our case, the adduction of $\mathrm{Mu}$ to the charged $\mathrm{C}_{60}$ molecule generates a radical species already identified in past experiments.[14] Being the fraction which repolarizes within this field range attributed to $\mathrm{C}_{60}-\mathrm{Mu}$ radicals (chemically equivalent to a hydrogen stably bound to $\mathrm{C}_{60}$ ), the relative amplitude indicates the propensity of the $\mathrm{C}_{60}$ (or $\left.\mathrm{C}_{60} \mathrm{H}_{\mathrm{y}}\right)$ molecule to further accept atomic hydrogen via a chemisorption process. Figure $3(a-$ $g$ ) shows the LF dependence of the initial asymmetries (repolarization curves), according to the fits of the muon spin evolution. For sake of clarity, the simulated repolarized curves for a muon interacting with a nuclear dipole, a $\mathrm{C}_{60}$ radical $\left(\mathrm{Mu}-\mathrm{C}_{60}\right)$ and a free $\mathrm{Mu}$ are also displayed in Figure 3(a). Although in heavily hydrogenated fullerides, such as $\mathrm{Pd}_{\mathrm{x}} \mathrm{Li}_{6} \mathrm{C}_{60} \mathrm{H}_{\mathrm{y}}$ and $\mathrm{Pt}_{\mathrm{x}} \mathrm{Li}_{6} \mathrm{C}_{60} \mathrm{H}_{\mathrm{y}}$, the formation of adduct radicals is not expected due to the saturation of available sites, a consistent 
fraction of polarization is still missing, proving that $\mathrm{C}_{60}$, in these compounds, is still capable to bind further hydrogen atoms. By comparing the low field initial asymmetries of $\operatorname{Pd}_{\mathrm{x}} \mathrm{Li}_{6} \mathrm{C}_{60} \mathrm{H}_{\mathrm{y}}$ and $\mathrm{Pt}_{\mathrm{x}} \mathrm{Li}_{6} \mathrm{C}_{60} \mathrm{H}_{\mathrm{y}}$ with the lower-grade hydrogenated compounds (e.g. $\left.\mathrm{Li}_{6} \mathrm{C}_{60} \mathrm{H}_{\mathrm{y}}\right)$ we observe that the repolarization amplitudes are only slightly decreased in the radical region. On the contrary, an extinction of the repolarization is expected in this region in the case of a saturated molecule. This allows us to speculate on the existence of hyper-hydrogenated states of $\mathrm{C}_{60}$, possibly overcoming the overall limit of $6 \mathrm{wt} \% \mathrm{H}_{2}$. These states might be accessible under different physical (e.g. temperature, $\mathrm{H}_{2}$ pressure) or chemical (e.g. intercalants, catalysts) conditions with respect to those explored so far. The fits of the LF repolarization data had been attempted trying different functions, i.e. isotropic, axial, or full-anisotropic radical and muonium, as well as their combinations, exploiting their analytical models.[21] In particular, the isotropic model of free $\mathrm{Mu}$, here corresponding to the endohedral species,[22] was also taken into account.
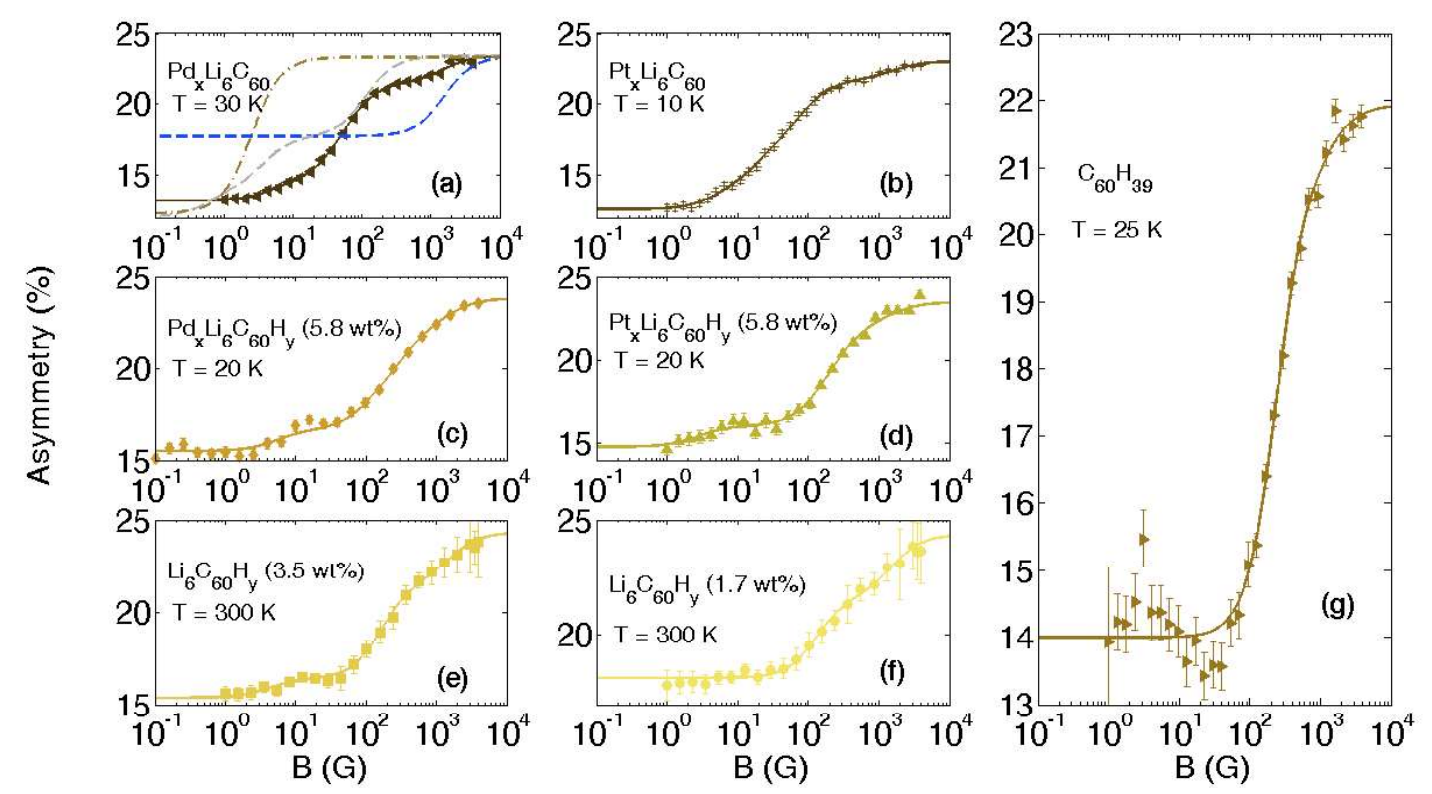

Figure 3: Repolarisation curves (symbols) and respective fits (solid lines) of $\mathrm{Li}_{6} \mathrm{C}_{60}$ based compound for different grades of hydrogenation (a-f) and for $\mathrm{C}_{60} \mathrm{H}_{39}(\mathrm{~g})$. Dashed lines in (a) represent the hypothetical curves for a muon interacting with nuclear dipolar moments (light brown), a Mu-C 60 radical (grey), and a free $\mathrm{Mu}$ (blue).

The fit functions can be generalized as:

$$
P_{\text {tot }}(B)=P_{M u}\left(A_{0}^{M u} ; B\right)+P_{r a d}\left(D_{1}, D_{2}, A_{0}^{r a d} ; B\right)+P_{\mu^{+}}
$$

Here $P_{M u}$ and $P_{\text {rad }}$ are, respectively, the fractions of endohedral $\left(\mathrm{Mu} @ \mathrm{C}_{60}\right)$ and radical $\left(\mathrm{Mu}-\mathrm{C}_{60}\right)$ muonium; $P_{\mu^{+}}$is a flat baseline; $A_{0}^{M u}$ and $A_{0}^{\text {rad }}$ represent the hyperfine parameters for the isotropic 
$\mathrm{Mu}$ and anisotropic radical respectively; $\mathrm{D}_{1}$ and $\mathrm{D}_{2}$ are the dipolar components for the latter and can be explained considering the Hamiltonian describing the hyperfine interaction:

$$
\mathcal{H}_{\text {hyp }}=\boldsymbol{S}_{\boldsymbol{e}} \cdot \hat{A} \cdot \boldsymbol{I}_{\boldsymbol{\mu}}
$$

Where $\boldsymbol{S}_{\boldsymbol{e}}$ and $\boldsymbol{I}_{\boldsymbol{\mu}}$ are the electron and muon spins and $\hat{A}$ is the hyperfine tensor:

$$
\hat{A}=\left(\begin{array}{ccc}
A_{0} & 0 & 0 \\
0 & A_{0} & 0 \\
0 & 0 & A_{0}
\end{array}\right)+\frac{1}{2}\left(\begin{array}{ccc}
2 D_{1} & 0 & 0 \\
0 & D_{2}-D_{1} & 0 \\
0 & 0 & -\left(D_{1}+D_{2}\right)
\end{array}\right)
$$

The fits are also reported, as solid lines, in Figure 3(a-g).

Excluding the samples $\mathrm{C}_{60} \mathrm{H}_{39}$ and $\mathrm{Li}_{6} \mathrm{C}_{60} \mathrm{H}_{\mathrm{y}}$ hydrogenated at $190{ }^{\circ} \mathrm{C}$ and 60 bar $\mathrm{H}_{2}$, data are well reproduced by the sum of an anisotropic radical and a free muonium, in addition to a flat baseline, corresponding to non-decaying diamagnetic muons $\left(\mu^{+}\right)$stopping in the sample holder.

Table 1: diamagnetic, radical and endohedral fractions present at low temperature for the different examined compounds. The $D_{1}$ and $D_{2}$ parameters are also reported for the anisotropic radical species.

\begin{tabular}{|c|c|c|c|c|c|c|c|}
\hline & $\mathrm{C}_{60} \mathrm{H}_{39}$ & $\mathrm{Pd}_{\mathrm{x}} \mathrm{Li}_{6} \mathrm{C}_{60}$ & $\mathrm{Pt}_{\mathrm{x}} \mathrm{Li}_{6} \mathrm{C}_{60}$ & $\begin{array}{c}\mathrm{Li}_{6} \mathrm{C}_{60} \mathrm{H}_{\mathrm{y}} \\
(1.7 \mathrm{wt} \%)\end{array}$ & $\begin{array}{c}\mathrm{Li}_{6} \mathrm{C}_{60} \mathrm{H}_{\mathrm{y}} \\
(3.5 \mathrm{wt} \%)\end{array}$ & $\begin{array}{c}\mathrm{Pd}_{\mathrm{x}} \mathrm{Li}_{6} \mathrm{C}_{60} \mathrm{H}_{\mathrm{y}} \\
(5.8 \mathrm{wt} \%)\end{array}$ & $\begin{array}{c}\mathrm{Pt}_{\mathrm{x}} \mathrm{Li}_{6} \mathrm{C}_{60} \mathrm{H}_{\mathrm{y}} \\
(5.8 \mathrm{wt} \%)\end{array}$ \\
\hline$\mu^{+}(\%)$ & $5(1)$ & $33(1)$ & $34(1)$ & $27(1)$ & $32(1)$ & $48(1)$ & $46(2)$ \\
\hline $\mathrm{Mu}-\mathrm{C}_{60}(\%)$ & $85(2)$ & $46(1)$ & $51(1)$ & $41(1)$ & $37(1)$ & $37(1)$ & $41(2)$ \\
\hline $\mathrm{Mu} @ \mathrm{C}_{60}(\%)$ & $10(3)$ & $21(1)$ & $15(1)$ & $32(1)$ & $31(1)$ & $15(3)$ & $12(4)$ \\
\hline $\mathrm{A}_{0}^{\text {rad }}(\mathrm{MHz})$ & $684(33)$ & $196(17)$ & $228(14)$ & $375(109)$ & $521(143)$ & $970(114)$ & $775(154)$ \\
\hline $\mathrm{D}_{1}(\mathrm{MHz})$ & 0 & $109(17)$ & $52(5)$ & 0 & $418(4)$ & $271(35)$ & $344(69)$ \\
\hline $\mathrm{D}_{2}(\mathrm{MHz})$ & 0 & $20(6)$ & $19(5)$ & 0 & $18(10)$ & $23(6)$ & $12(5)$ \\
\hline
\end{tabular}

The presence of a free $\mathrm{Mu}$ has long been known in fullerene and fullerides and attributed to endohedral species.[17] Anyway, to the best of our knowledge, this is the first report of an endohedral muonium in hydrogenated fullerides and fullerene. Due to the high number of parameters, the $\mathrm{Mu} @ \mathrm{C}_{60}$ hyperfine field was fixed at $1542 \mathrm{G}$ (the value of free $\mathrm{Mu}$ ), although its value is expected to be slightly affected (of the order of $0-2.5 \%$ ) by its endohedral status.[17] Especially for the highly-hydrogenated systems, where the radical hyperfine $\left(\mathrm{A}_{0}{ }^{\mathrm{rad}}\right)$ approaches the same order of magnitude of the muonium hyperfine $\left(\mathrm{A}_{0}{ }^{\mathrm{Mu}}\right)$, the correlation between the fit amplitudes of the two species is large, resulting in an increase of the errors. The repolarization of $\mathrm{C}_{60} \mathrm{H}_{39}$ deserves a separate consideration. The fit based on a model containing an isotropic radical 
and the endohedral $\mathrm{Mu}$, well reproduces the LF repolarization data. The same has been found for $\mathrm{Li}_{6} \mathrm{C}_{60} \mathrm{H}_{\mathrm{y}}$ hydrogenated at $190{ }^{\circ} \mathrm{C}$ and 60 bar $\mathrm{H}_{2}$. In fact, for these compounds the non- $f c c$ or $-b c c$ structure is likely to be originated by a broad variety of $\mathrm{C}_{60} \mathrm{H}_{\mathrm{y}}$ isomers. The respective radicals share similar hyperfine values but different anisotropies, thus the resulting repolarization curve resembles the isotropic radical case. Figure 4 displays the isotropic hyperfine parameter, $\mathrm{A}_{0}{ }^{\mathrm{rad}}$, as calculated for the samples here investigated and for others hydrogenated and non-hydrogenated alkali clusters intercalated fullerides.

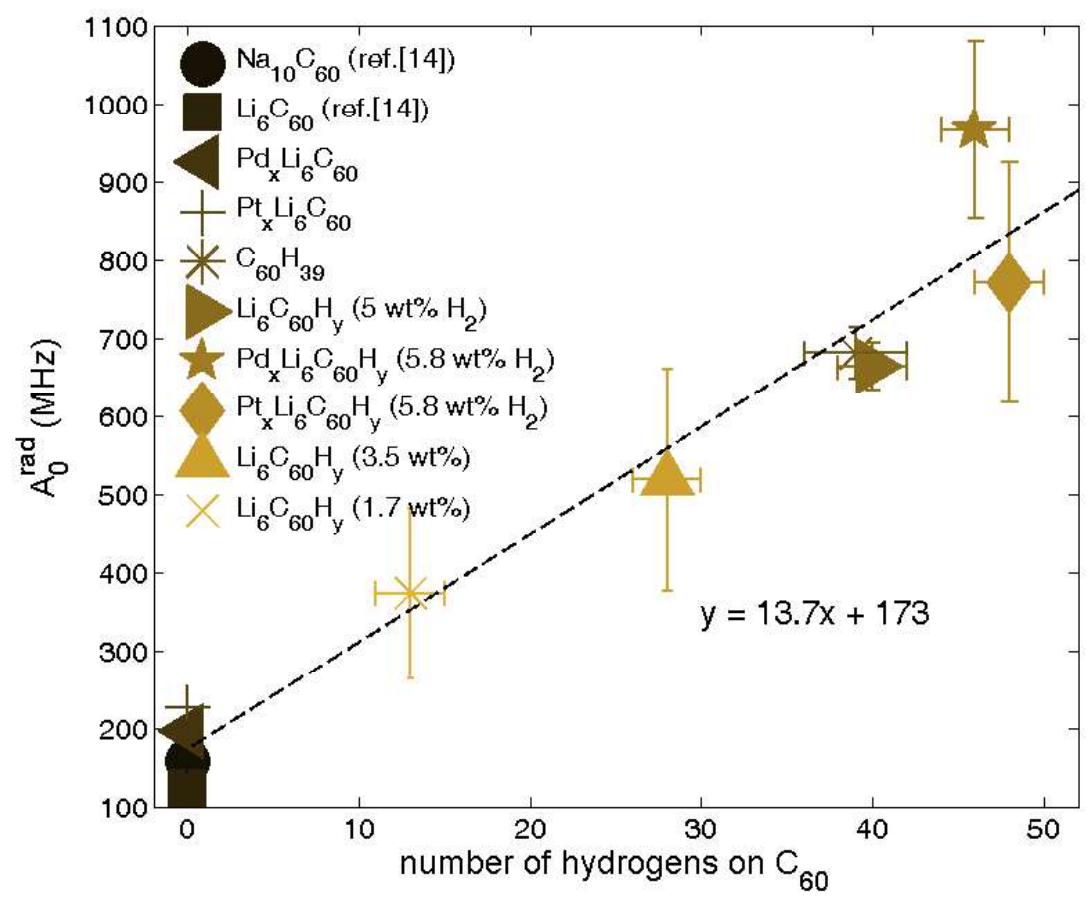

Figure 4: fit radical hyperfine frequency for various degree of hydrogenation in different $C_{60}$ based compounds. The dashed line is a linear fit to data, whose parameters are also reported.

A monotonic relation is observed between the hydrogenation degree and $\mathrm{A}_{0}^{\text {rad }}$. This can be explained by considering the effect of the increasing number of neighbouring hydrogen atoms lying on the $\mathrm{C}_{60}$ surface on the hyperfine interaction. The isotropic hyperfine frequency is related to the probability to find the radical electron on the adducted Mu by $A_{0}=\frac{2}{3} \mu_{0} \gamma_{e} \gamma_{\mu} \hbar^{2}|\psi(0)|^{2}$, where $\mu_{0}$ is the vacuum magnetic permeability, $\gamma_{e}$ and $\gamma_{\mu}$ are the electron and the muon gyromagnetic ratios respectively, and $|\psi(0)|^{2}$ is the electron density at the muon site. $\mathrm{A}_{0}{ }^{\mathrm{Mu}}$ reaches its maximum value for a free $\mathrm{Mu}$ (i.e. $4.463 \mathrm{GHz}$ ), it is slightly reduced for an endohedral $\mathrm{Mu}$, and decreases significantly in case of radical species (generally in the order of $10^{1}-10^{3} \mathrm{MHz}$ ), where the radical electron can be delocalized over many nuclei. The high number of hydrogen atoms bound to 
carbons induces the localization of the radical electron near to the adducted $\mathrm{Mu}$ and underpins the increased value of $\mathrm{A}_{0}^{\text {rad }}$ with respect a non-hydrogenated fullerene. In particular, for highly hydrogenated materials, such as Pt and Pd decorated fullerides, this value seems to reach 750-1000 MHz. The fractions of muon and muonium species, such as the values of the hyperfine parameters of the investigated samples are reported in Figure 5 displays the temperature dependence of the paramagnetic fraction (Mu and radical) for PdxLi6C60, PdxLi6C60Hy, and $\mathrm{C} 60 \mathrm{H} 39$, as calculated from the fit of the diamagnetic component in a TF experiment in $20 \mathrm{G}$. Due to the different nature of the experiment and the lowest grade of counts acquired in the TF polarizations, the absolute values fit for the paramagnetic fractions (Mu-C60) display some discrepancies and higher errors compared to the LF experiments. Similarly to what observed in Li6C60 and Na10C60,[14] even in $\mathrm{C} 60 \mathrm{H} 39$ and $\mathrm{Pt} / \mathrm{PdxLi6C60Hy}$ and $\mathrm{Li6C60Hy}$ the low temperature promotes the production of radicals. .

Comparing the fulleride samples after the hydrogenation, the radical amplitudes decrease of about $20 \%$. An exception is made for $\mathrm{C}_{60} \mathrm{H}_{39}$ hydrofullerene, showing the highest fraction of radical. This suggests that a non-intercalated molecule, rather than a hydrofulleride, is more likely to promote the formation of muoniated species (i.e. C-H bonds). Whether this effect is due to the absence of charge on the hydrofullerene (in the hydrofullerides the intercalated metals donate charges to $\mathrm{C}_{60} \mathrm{H}_{\mathrm{y}}$, while $\mathrm{C}_{60} \mathrm{H}_{39}$ is a neutral molecule), rather than a lower steric hindrance, cannot be clarified by this experiment.

The table also reports the two independent parameters, $\mathrm{D}_{1}$ and $\mathrm{D}_{2}$, describing the dipolar components of the hyperfine tensor, whose values depend on the radical anisotropy (e.g. $\mathrm{D}_{1}=\mathrm{D}_{2}=0$ for an isotropic muonium). The radical electron fills a $\mathrm{C}_{60} \pi$ orbital, which is intrinsically anisotropic, reflecting in a strong dipolar component, $D_{1} \neq D_{2} \neq 0$. As expected, the increased value of $A_{0}^{r a d}$ in these materials is followed by an increase of $\mathrm{D}_{1}$. It is also worth noting that hydrogenated systems exhibit higher values of $\mathrm{D}_{1}$, although the ratio between $A_{0}^{\text {rad }}$ and $\mathrm{D}_{1}$ does not depend on the hydrogen content. Figure 5 displays the temperature dependence of the paramagnetic fraction $(\mathrm{Mu}$ and radical) for $\mathrm{Pd}_{\mathrm{x}} \mathrm{Li}_{6} \mathrm{C}_{60}, \mathrm{Pd}_{\mathrm{x}} \mathrm{Li}_{6} \mathrm{C}_{60} \mathrm{H}_{\mathrm{y}}$, and $\mathrm{C}_{60} \mathrm{H}_{39}$, as calculated from the fit of the diamagnetic component in a TF experiment in $20 \mathrm{G}$. Due to the different nature of the experiment and the lowest grade of counts acquired in the TF polarizations, the absolute values fit for the paramagnetic fractions $\left(\mathrm{Mu}-\mathrm{C}_{60}\right)$ display some discrepancies and higher errors compared to the LF experiments. Similarly to what observed in $\mathrm{Li}_{6} \mathrm{C}_{60}$ and $\mathrm{Na}_{10} \mathrm{C}_{60},[14]$ even in $\mathrm{C}_{60} \mathrm{H}_{39}$ and $\mathrm{Pt} / \mathrm{Pd}_{\mathrm{x}} \mathrm{Li}_{6} \mathrm{C}_{60} \mathrm{H}_{\mathrm{y}}$ and $\mathrm{Li}_{6} \mathrm{C}_{60} \mathrm{H}_{\mathrm{y}}$ the low temperature promotes the production of radicals. On the other hand, a higher temperature $\left(150-250^{\circ} \mathrm{C}\right)$ is normally required to trigger the hydrogen absorption process on these 
materials through the dissociation of hydrogen molecules by the intercalated alkali or transition metals clusters, although above room temperature the chemisorption of hydrogen atoms, as shown by these results (Figure 5), is less strongly promoted.

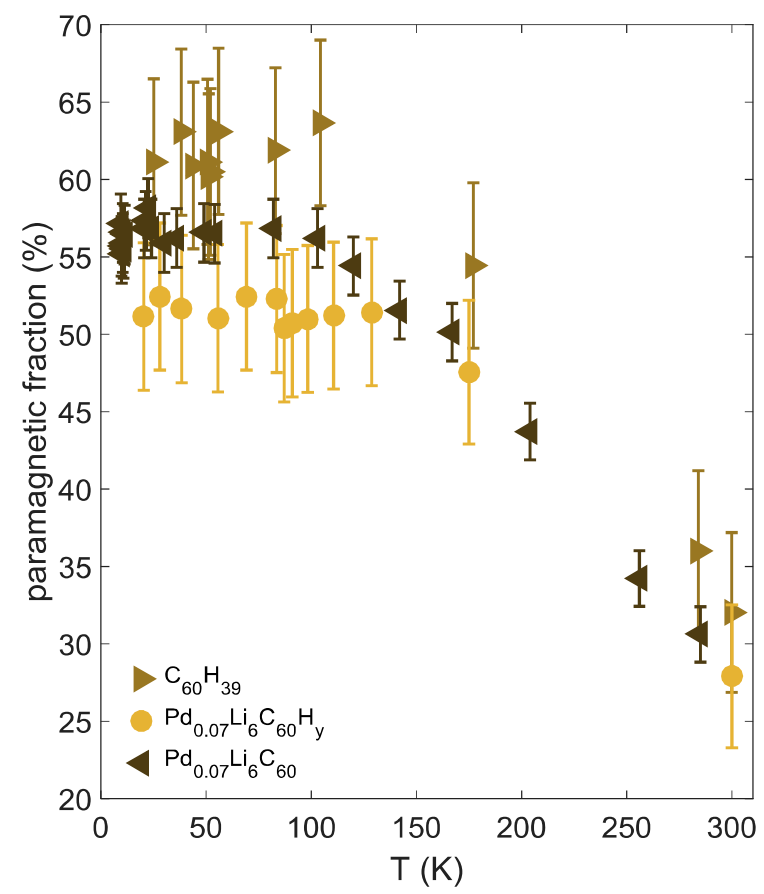

Figure 5: Temperature dependence of the paramagnetic fractions (muonium and radical) as calculated from TF experiments for selected samples.

\section{Conclusions}

Different lithium intercalated fullerene compounds have been synthesized and hydrogenated at various stages and the maximum hydrogenation degree has been achieved by adding $\mathrm{Pt}$ and $\mathrm{Pd}$ catalysts. The ability of these materials to chemisorb hydrogen has been investigated by muon spin relaxation ( $\mu \mathrm{SR}$ ) technique. Interestingly, the formation of endohedral muonium has been observed for the first time in hydrogenated fullerene and fullerides. Contrary to what expected, highly hydrogenated fullerides still show a remarkable propensity to additional hydrogen chemisorption, although with a lower extent, suggesting that an even higher degree of hydrogenation can be achieved. The addition of transition metal nanoparticles, although effective to increase the amount of absorbed hydrogen, seems not to be sufficient to allow the maximum grade of hydrogenation. The radical formation, related to the hydrogen chemisorption process, is confirmed to be favoured at low temperature. Finally, we observed that the muon-electron hyperfine parameter, $\mathrm{A}_{0}{ }^{\mathrm{rad}}$, monotonically increases with the number of hydrogen atoms bound to $\mathrm{C}_{60}$. This work demonstrate 
that its value might be adopted to empirically predict the average grade of hydrogenation in fullerides.

\section{Acknowledgements}

This work is supported by Cariplo Foundation (Project number 2013-0592, "Carbon based nanostructures for innovative hydrogen storage systems") and from the European Union's Horizon 2020 research and innovation programme under the Marie Skłodowska-Curie grant agreement No 665593 awarded to the Science and Technology Facilities Council. For the $\mu$ SR experiment, this project has received funding from the European Union's $7^{\text {th }}$ Framework Programme for research, technological development and demonstration under the NMI3-II Grant Number 283883. We would also like to acknowledge Dr. Francis Pratt and Dr. Mark Telling for the technical support during the $\mu$ SR experiments and Dr. Gavin Stenning for help on the Xenox Nano-inXider instrument in the Materials Characterisation Laboratory at the ISIS Neutron and Muon Source.

\section{References}

[1] Teprovich JA, Knight DA, Wellons MS, Zidan R. Catalytic effect of fullerene and formation of nanocomposites with complex hydrides: NaAlH4 and LiAlH4. J Alloys Compd 2011;509:S562-6. doi:10.1016/j.jallcom.2010.10.031.

[2] Teprovich J a., Knight D a., Peters B, Zidan R. Comparative study of reversible hydrogen storage in alkali-doped fulleranes. J Alloys Compd 2013;580:S364-7. doi:10.1016/j.jallcom.2013.02.024.

[3] Mauron P, Remhof A, Bliersbach A, Borgschulte A, Züttel A, Sheptyakov D, et al. Reversible hydrogen absorption in sodium intercalated fullerenes. Int J Hydrogen Energy 2012;37:14307-14. doi:10.1016/j.ijhydene.2012.07.045.

[4] Mauron P, Gaboardi M, Pontiroli D, Remhof A, Riccò M, Züttel A. Hydrogen Desorption Kinetics in Metal Intercalated Fullerides. J Phys Chem C 2015;119:1714-9. doi:10.1021/jp511102y.

[5] Gaboardi M, Duyker S, Milanese C, Magnani G, Peterson VK, Pontiroli D, et al. In Situ Neutron Powder Diffraction of Li 6 C 60 for Hydrogen Storage. J Phys Chem C 2015;119:19715-21. doi:10.1021/acs.jpcc.5b06711.

[6] Knight D A, Teprovich J A, Summers A, Peters B, Ward P a, Compton RN, et al. Synthesis, characterization, and reversible hydrogen sorption study of sodium-doped fullerene. Nanotechnology 2013;24:455601. doi:10.1088/0957-4484/24/45/455601. 
[7] Teprovich JA, Washington AL, Dixon J, Ward PA, Christian JH, Peters B, et al. Investigation of hydrogen induced fluorescence in $\mathrm{C}_{60}$ and its potential use in luminescence down shifting applications. Nanoscale 2016:18760-70. doi:10.1039/C6NR05998H.

[8] Teprovich JA, Wellons MS, Lascola R, Hwang S-J, Ward P a, Compton RN, et al. Synthesis and characterization of a lithium-doped fullerane (Lix-C60-Hy) for reversible hydrogen storage. Nano Lett 2012;12:582-9. doi:10.1021/n1203045v.

[9] Aramini M, Milanese C, Pontiroli D, Gaboardi M, Girella A, Bertoni G, et al. Addition of transition metals to lithium intercalated fullerides enhances hydrogen storage properties. Int J Hydrogen Energy 2014;39:2124-31. doi:10.1016/j.ijhydene.2013.11.087.

[10] Wang Q, Jena P. Density Functional Theory Study of the Interaction of Hydrogen with Li6C60. J Phys Chem Lett 2012;3:1084-8. doi:10.1021/jz3002037.

[11] Cataldo F, Iglesias-Groth S, editors. Fulleranes. vol. 2. Dordrecht: Springer Netherlands; 2010. doi:10.1007/978-1-4020-9887-1.

[12] Maidich L, Pontiroli D, Gaboardi M, Lenti S, Magnani G, Riva G, et al. Investigation of Li and H dynamics in Li6C60 and Li6C60Hy. Carbon N Y 2016;96:276-84.

doi:10.1016/j.carbon.2015.09.064.

[13] Sugiyama J, Ikedo Y, Noritake T, Ofer O, Goko T, Månsson M, et al. Microscopic indicator for thermodynamic stability of hydrogen storage materials provided by positive muon-spin rotation. Phys Rev B 2010;81:92103. doi:10.1103/PhysRevB.81.092103.

[14] Aramini M, Gaboardi M, Vlahopoulou G, Pontiroli D, Cavallari C, Milanese C, et al. Muon spin relaxation reveals the hydrogen storage mechanism in light alkali metal fullerides. Carbon N Y 2014;67:92-7. doi:10.1016/j.carbon.2013.09.063.

[15] Gaboardi M, Cavallari C, Magnani G, Pontiroli D, Rols S, Riccò M. Hydrogen storage mechanism and lithium dynamics in Li12C60 investigated by $\mu$ SR. Carbon N Y 2015;90:130-7. doi:10.1016/j.carbon.2015.03.072.

[16] Riccò M, Pontiroli D, Mazzani M, Choucair M, Stride JA, Yazyev O V. Muons probe strong hydrogen interactions with defective graphene. Nano Lett 2011;11:4919-22. doi:10.1021/n1202866q.

[17] Kiefl R, Duty T, Schneider J, MacFarlane A, Chow K, Elzey J, et al. Evidence for endohedral muonium in $K_{-}\{x\}$ C_ $\{60\}$ and consequences for electronic structure. Phys Rev Lett 1992;69:20058. doi:10.1103/PhysRevLett.69.2005.

[18] Pratt F. WIMDA: a muon data analysis program for the Windows PC. Phys B Condens Matter 2000;289-290:710-4. doi:10.1016/S0921-4526(00)00328-8. 
[19] Hall LE, McKenzie DR, Attalla MI, Vassallo AM, Davis RL, Dunlop JB, et al. The structure of hydrogenated fullerene (C60H36). J Phys Chem 1993;97:5741-4. doi:10.1021/j100123a046.

[20] Schenck A. Muon spin rotation spectroscopy: Principles and applications in solid state physics. (C) Adam Hilger Ltd; 1985.

[21] Pratt FL. Repolarization of anisotropic muonium in orientationally disordered solids. Philos Mag Lett 1997;75:371-80. doi:10.1080/095008397179444.

[22] MacFarlane W, Kiefl R, Dunsiger S, Sonier J, Chakhalian J, Fischer J, et al. Muon-spin-relaxation studies of the alkali-fulleride superconductors. Phys Rev B 1998;58:1004-24. doi:10.1103/PhysRevB.58.1004. 